\title{
MFT a new diagnostic tool to check the balance in a normal healthy individuals
}

\author{
Snehal K. Patel ${ }^{1}$, Mahendra L. Shende ${ }^{2}$, and Subhash M. Khatri ${ }^{3}$ \\ I(Postgraduate student, College of Physiotherapy, PIMS, Loni- 413 736, India) \\ 2(Associate professor, College of Physiotherapy, PIMS, Loni- 413 736, India) \\ 3(Professor and Principal, College of Physiotherapy, PIMS, Loni- 413 736, India)
}

\begin{abstract}
Background: My Fitness Trainer (MFT) balance board was produced for skiers and then surfers to practice their skills in the off season. However, there was hardly any study done by using this balance board in normal individuals. Objective: To find out the effect of My Fitness Trainer Balance Board Training on normal healthy individuals. Study Design: Pre and Post. Materials and Methods: Twenty (10 males, 10 females) healthy normal individuals between the age of 20-30 years. Individuals were made to stand in the Electronic Balance Board and the computer screen was kept in front of him for giving biofeedback and was trained for forward, backward and sideways balance re-training. At the end of training, his score was displayed in the screen \& recorded for 30, 45, 60 seconds. Training was given for 30 minutes once/ week for 6 weeks. Results: The results showed improvement in the balance score after 6 weeks of training programme ( $p<0.01)$. Conclusion: MFT Balance board is of a great use for training purpose.
\end{abstract}

Keywords: Balance, Propioception, Stability

\section{Introduction}

MFT (My Fitness Trainer) balance board was produced for skiers and then surfers to practice their skills in the off season and at night, a balance board is a device that has come to be used for training in all sports and martial arts, physical fitness and for non-athletic purposes. New MFT Balance boards and discs feature a unique modular design that is easily adaptable for athletics training therapy, rehabilitation, senior fitness. It was developed by 'Ewald Aigner', trainer for the Austrain ski team for 5 years. It is used to develop balance, motor coordination skills, weight distribution and core strength [1]. As the age advanced to avoid injurious falls; to prevent sports injuries, especially to knee and ankle, rehabilitation after injuries to several parts of the body [23]. Uses of a balance board that are distant from the athletic purpose of its origin have gradually become more common to expand neural networks that enable the left and right hemispheres of the brain to communicate with each other, thereby increasing its efficiency to develop sensory integration and cognitive skills in children with developmental disorders[4-6].

MFT S3 test is a reliable and valid balance measurement system for performance and Sensorimotor regulation during lateral and forward, backward test [7]. The test system consist of a uniaxial unstable platform with an integrated sensor, which records all discrepancies in the horizontal plane. All function of center of gravity are measured and transformed into stability, sensorimotor and symmetry indexes to define the individual state of balance. For dynamic standing stability on an unstable support surface, this shows good reliability, objectivity and validity [8]. However, in normal individuals also some amount of balance was impaired hence, the objective of the study to find out the effect of MFT Balance Board Training on normal healthy individuals.

\subsection{Participants:}

\section{Methods}

1) Source of data: Pravara Institute Of Medical Sciences, College of Physiotherapy, Department of Physiotherapy, Loni (BK)-413 736, Taluka-Rahata, District-Ahmednagar, Maharashtra state, India

2) Study design: Pre and post test

3) Duration of study: 6 weeks, Thrice/week, for 30 minutes

4) Sample size: 20 (10 males, 10 females)

\section{Inclusion criteria:}

- Normal healthy individuals

- Age:20-30 years

- Gender: Both males and females

- Willing to participate in the study 


\section{Exclusion criteria:}

- Individuals with musculoskeletal impairments like, ankle sprain, plantar fascitis

- Individuals with fracture or other diseases

- History of dizziness

- History of inner ear disorders.

- History of low back pain or hip pathology/pain

- Uncorrected visual problems

\subsection{Outcome measures:}

- The Electronic Balance Board from MFT® (www.myfitnesstrainer.net) MFT Software Balance Test 1.7 (Fig.1)

Scoring: 1= Excellent Stability, 2= Good Stability, 3= Improvable Stability, 4= Disappointing Stability, 5= Bad Stability

2.3 Procedures: 20 individuals (10 males, 10 females) were stand on MFT balance board. Individual was made to stand in the Electronic Balance Board and the computer screen was kept in front of him for giving biofeedback and was trained for forward, backward and sideways balance training (Fig.2, 3). At the end of training, his score was displayed in the screen \& recorded for 30, 45, 60 seconds (Fig.4). Training was given for 30 minutes once/ week for 6 weeks.

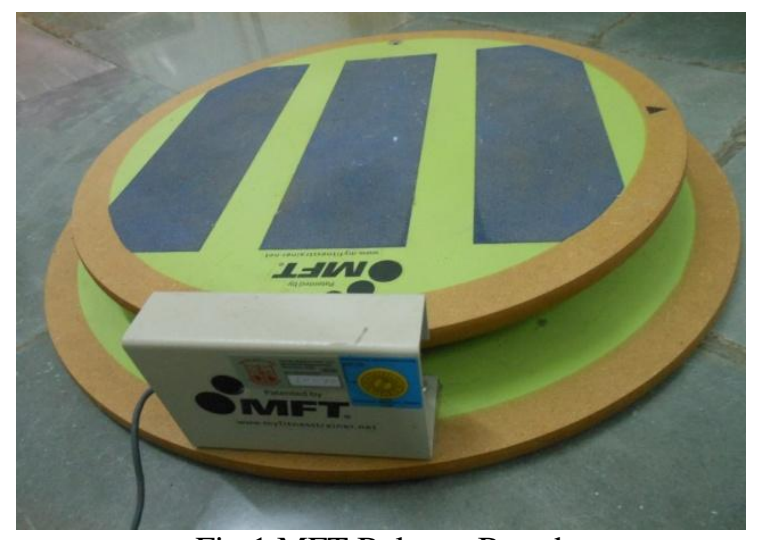

Fig.1 MFT Balance Board

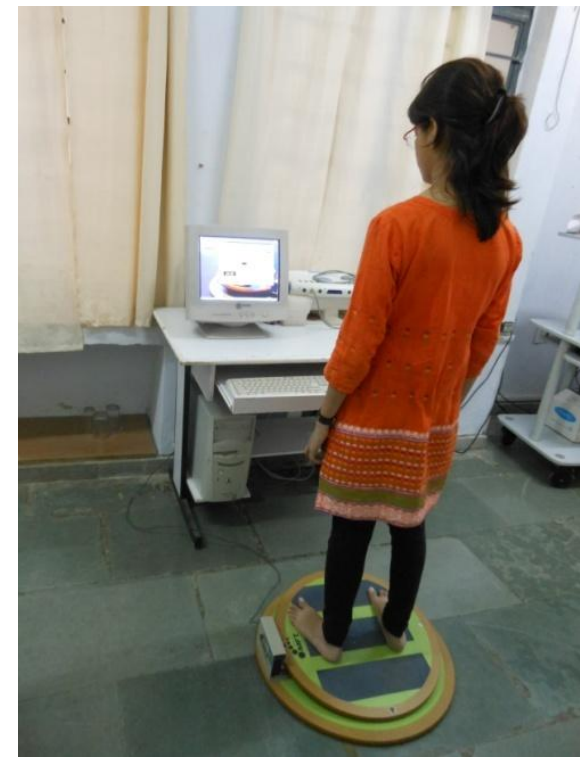

Fig.2 Forward \& backward Balance training-Female

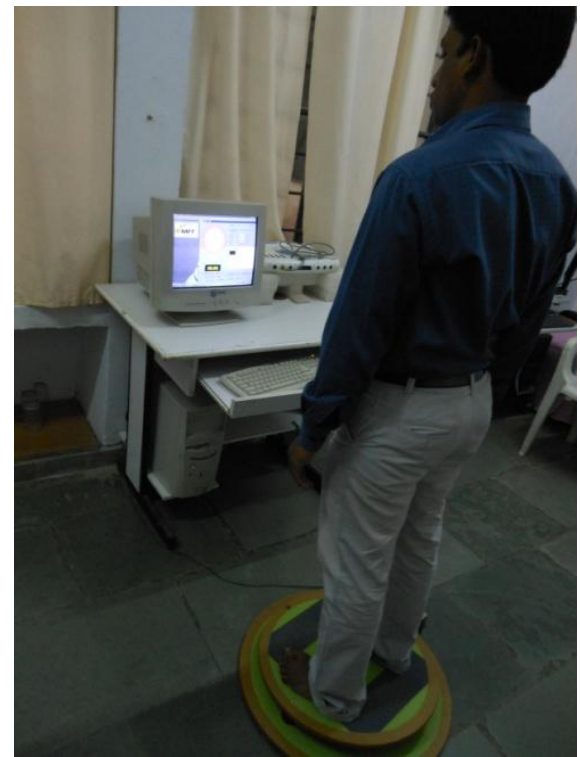

Fig.3 Sideways Balance training-Male 


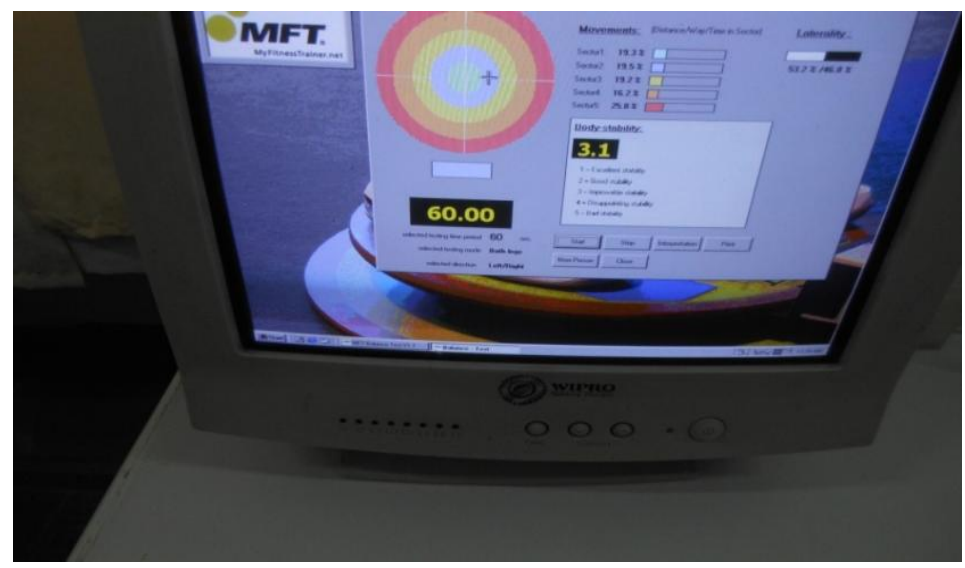

Fig.4 Balance Board Score

\section{Data analysis and Results}

Data were analyzed using trial version Graph Pad Instat software 3.10. The data were entered into an excel spread sheet, tabulated and subjected to statistical analysis. Various statistical measures used for this study which includes mean, standard deviation (SD) and test of significance such as paired and unpaired ' $t$ ' test. The baseline demographic data age, height and weight were analyzed by descriptive statistics.

Demographic variables between the males and females were evaluated by unpaired ' $t$ ' test (Table 3.1). Paired ' $t$ ' test was used to compare the mean score of males at the end of $1^{\text {st }}$ and $6^{\text {th }}$ week (Table 3.2, 3.3). For this purpose, data was collected by the primary investigator and the comparison of scores was made at $1^{\text {st }}$ week and $6^{\text {th }}$ week. The results were concluded to be statistically significant with $p<0.05$ and highly significant with $p$ $<0.01$.

Table 3.1: Demographic and clinical characteristics

\begin{tabular}{|c|c|c|c|}
\hline & $\begin{array}{c}\text { Males } \\
\text { Mean } \pm \text { S.D }\end{array}$ & $\begin{array}{c}\text { Females } \\
\text { Mean } \pm \text { S.D }\end{array}$ & p value \\
\hline Age (years) & $26.2 \pm 1.75$ & $26.1 \pm 1.37$ & 0.88 \\
\hline Height (centimeters) & $167.2 \pm 7.91$ & $164.6 \pm 6.27$ & 0.42 \\
\hline Weight (kilograms) & $63.6 \pm 9.64$ & $54.6 \pm 9.69$ & 0.65 \\
\hline
\end{tabular}

Table 3.2: Comparison of Males at the end of $1^{\text {st }}$ and $6^{\text {th }}$ week

\begin{tabular}{|c|c|c|c|c|c|}
\hline MALES & $1^{\text {st }}$ week & $6^{\text {th }}$ week & t value & $\mathrm{p}$ value & Result \\
\hline $\begin{array}{c}\text { Mean } \pm \text { S.D } \\
\text { (30seconds) }\end{array}$ & $4.02 \pm 0.64$ & $2.6 \pm 0.97$ & 8.4 & $<0.05^{\text {a }}$ & Significant \\
\hline (45seconds) & $3.86 \pm 0.60$ & $2.5 \pm 0.89$ & 8.8 & $<0.05^{\text {a }}$ & Significant \\
\hline (60seconds) & $3.66 \pm 0.67$ & $2.4 \pm 0.84$ & 9.0 & $<0.01^{\text {a }}$ & $\begin{array}{c}\text { Highly } \\
\text { Significant }\end{array}$ \\
\hline
\end{tabular}

Where: Analyzed by student paired ' $t$ ' test

Table 3.3: Comparison of Females at the end of $1^{\text {st }}$ and $6^{\text {th }}$ week

\begin{tabular}{|c|c|c|c|c|c|}
\hline FEMALES & $1^{\text {st }}$ week & $6^{\text {th }}$ week & $\mathrm{t}$ value & $\mathrm{p}$ value & Result \\
\hline $\begin{array}{l}\text { Mean } \pm \text { S.D } \\
\text { (30seconds) }\end{array}$ & $4.0 \pm 0.54$ & $2.9 \pm 0.35$ & 8.0 & $<0.05^{\text {a }}$ & Significant \\
\hline (45seconds) & $3.9 \pm 0.52$ & $2.4 \pm 0.39$ & 8.9 & $<0.05^{\text {a }}$ & Significant \\
\hline (60seconds) & $3.5 \pm 0.52$ & $2.2 \pm 0.53$ & 8.8 & $<0.01^{\text {a }}$ & $\begin{array}{c}\text { Highly } \\
\text { Significant }\end{array}$ \\
\hline
\end{tabular}

Where: ${ }^{a}$ Analyzed by student paired ' $t$ ' test 


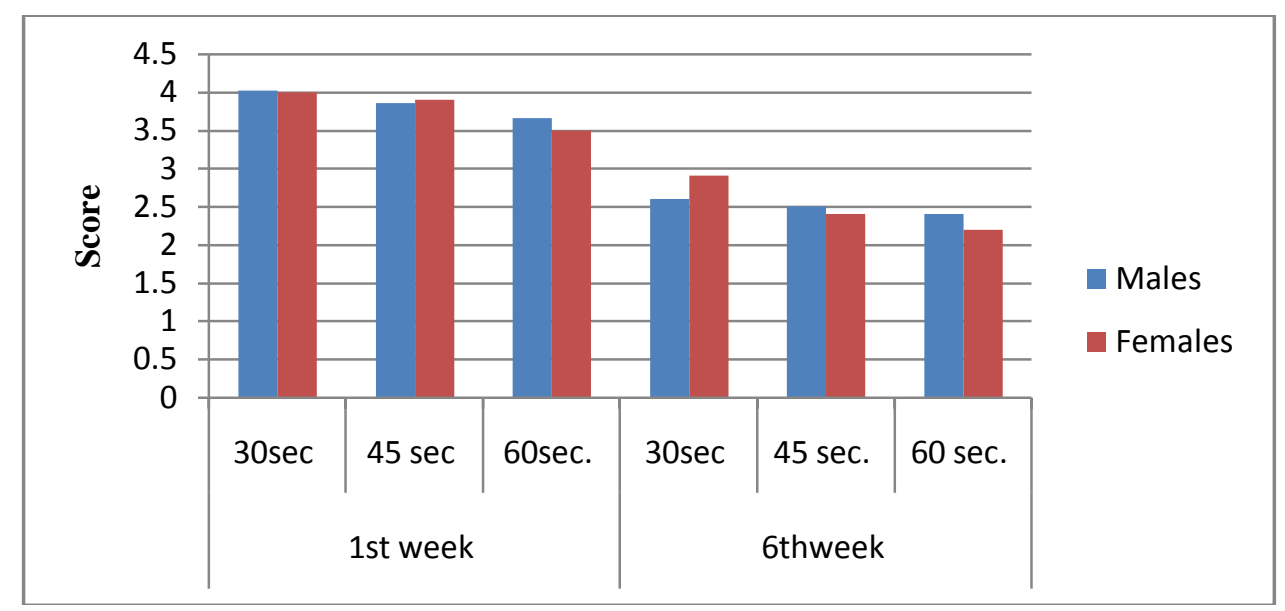

Inference: Mean score of both males and females were showing good stability at $6^{\text {th }}$ week compared to $1^{\text {st }}$ week

The results of this study showed improvement in the balance score with 60 seconds training after 6 weeks of training program. There were no significant differences between males and females when genders were compared.

\subsection{Discussion:}

\section{Discussion and Conclusion}

Balance and equilibrium constitute a complex reflexive response initiated by three primary sensory system (Vestibular, Visual and somatosensory) and coordinated by central nervous system. Until about twenty years ago simple behavioural tests such as, Romberg and Mann test were used to test postural control. More recently computer posturography has been developed and evaluated (Turner 1998). These devices allow the assessment of balance function more exactly, objectively and efficiently [9].

Improvement in balance score after intervention period this could be due to training or conditioning enhancement of non postural muscular use pattern, compensatory postural strategies, increase in neuro transfer between brain and effector muscle through descending pathway, facilitation of neural pathway, enhancement of vestibulocochlear pathway, sensory motor integration and neuroplasticity. In addition by giving the individual visual feedback, they become more aware of body displacement and orientation in space, they were able to integrate somatosensory and visual information in relation to stance and movement, which may recalibrate deficient proprioceptive information and compensate the Sensorimotor deficit [10-13].

Information regarding body position, gravity, musculoskeletal activity, tactile and visual feedback and other input provides the nervous system with the information required to maintain balance during daily activities taking place in an ever changing environment. Several studies have utilized a balance board as a way to demonstrate functional adaptation of spinal reflex in healthy and elderly population [14-15]. In one study CNS adaptation was correlated with clinical outcome of improved static balance, providing a direct connection between the sensorimotor system and measure of postural control [16].

Movement at ankle during rehabilitation is important in producing the desired training adaptations. These studies measures slightly different aspect of sensorimotor system. More work need to be done in this area for clinician to understand the physiological mechanism involved in the change that are occurring with balance training. A 2008 review found that balance training may decrease the risk of acute injury.

Most researchers have utilized conventional clinical rehabilitation protocols to determine the potential changes in these procedures produce. Studies of change in physiological or clinical measures over time typically assess changes before and after 4-6 weeks of training intervention [17-19]. Training occurring 3-5 times per week and lasting 10-30 minutes per session[20].

4.2 Conclusion: MFT Balance board is of a great use and helps overcome day today barriers. It used for training purpose. 


\subsection{Limitation of present study: Small sample size}

4.4 Suggestion for Future research: Anthropometric variables represented by body mass index influence by balance performance with eyes close, By using various balance scales in normal and disease individuals.

\section{Acknowledgment}

I would like to thank Dr. S. S. Jogdand, Bhushan Vichare, Daveshree Gupta and all the participants of this study in helping me to complete the study successfully.

\section{Funding: Nil}

Conflict of interest: None declared

\section{REFERENCES}

[1] Waddington G.S. and Adams, R.D., The Effect of a 5-Week Wobble-Board Exercise Intervention on Ability to Discriminate Different Degrees of Ankle Inversion, Barefoot and Wearing Shoes, Journal of the American Geriatrics Society, 52(4), 2004.

[2] Aaltonen, Karjalainen, H, Heinonen, A. Parkkari, J and Kujala, Prevention of Sports Injuries: Systematic Review of Randomized Controlled Trial, Archives of Internal Medicine (of the Journal of the American Medical Association), 167 (15), 2007, 13-27.

[3] McGuine, T.A., Keene, J.S., The Effect of a Balance Training Program on the Risk of Ankle Sprains in High School Athletes, American Journal of Sports Medicine, 34(7), 2006, 15-20.

[4] Caraffa, A., Cerulli, G., Projetti, M., Aisa, G. and Rizzo, A, Prevention of Anterior Cruciate Ligament Injuries in Soccer: A Prospective Controlled Study of Proprioceptive Training, Knee Surgery, Sports Traumatology, Arthroscopy, 4(1), 1996.

[5] Rhoads, Jarett A., Anterior Cruciate Ligament Injury Prevention Programs Impact on Knee Injury Rates in the Athletic Female: A Synthesis of the Research Literature, a masters thesis at the State University of New York College at Brockport: systematic review of eight published trials, three of which tested balance boards.

[6] McKeon PO, Hertel J., Systematic review of postural control and lateral ankle instability, part II: is balance training clinically effective? J Athl Train, 43(3), 2008,305-315.

[7] Raschner, C., Lembert, S., Platzer, H. P., Patterson, C., Hilden, T., \& Lutz, M. (2008). [S3-check--evaluation and generation of normal values of a test for balance ability and postural stability]. Sportverletzungen und Sportschaden, 22, 2008, 100-5.

[8] Gaerlan, Mary Grace, The role of visual, vestibular, and somatosensory systems in postural balance" (2010). UNLV Theses/ Dissertations/Professional Papers/Capstones. Paper 357. http://digitalscholarship.unlv.edu/thesesdissertations/357

[9] Michaela Gstöttner, Andreas Neher, Arne Scholtz, Martin Millonig, Sandra Lembert, and Christian Raschner, Balance Ability and Muscle Response of the Preferred and Nonpreferred Leg in Soccer Players, Motor Control,13, 1996, $218-231$.

[10] Walker C, Brouwer BJ, Culham EG, Use of visual feedback in retraining balance following acute stroke, Phys Ther 80, 2000, 886-895.

[11] Cheng PT, Wang CM, Chung CY, Chen CL (2004) Effects of visual feedback rhythmic weight-shift training on hemiplegic stroke patients, Clin Rehabil, 18, 2004, 747-753.

[12] Dault MC, de Haart M, Geurts AC, Arts IM, Nienhuis B, Effects of visual center of pressure feedback on postural control in young and elderly healthy adults and in stroke patients, Hum Mov Sci 22, 2003, 221-236.

[13] Mulder T, Hulstyn W, Sensory feedback therapy and theoretical knowledge of motor control and learning, Am J Phys Med 63, 1984, 226-244.

[14] Trimble MH, Koceja DM, Modulation of the triceps surae H-reflex with training, Int J Neurosci, 76(3-4), 1994, 293-303.

[15] Trimble MH, Koceja DM, Effect of a reduced base of support in standing and balance training on the soleus H-reflex, Int $J$ Neurosci, 106(1-2), 2001, 1-20.

[16] Mynark RG, Koceja DM., Down training of the elderly soleus H reflex with the use of a spinally induced balance perturbation, $J$ Appl Physiol, 93(1), 2002, 127-133.

[17] Kidgell DJ, Horvath DM, Jackson BM, Seymour PJ., Effect of six weeks of dura disc and mini-trampoline balance training on postural sway in athletes with functional ankle instability, J Strength Cond Res, 21(2), 2007, 466-469.

[18] Sefton JM, Yarar C, Hicks-Little CA, Six weeks of balance training improves sensorimotor function in individuals with chronic ankle instability, J Orthop Sports Phys Ther, 41(2), 2011, 81-89.

[19] McKeon PO, Paolini G, Ingersoll CD, Effects of balance training on gait parameters in patients with chronic ankle instability: a randomized controlled trial, Clin Rehabil, 23(7), 2009, 609-621.

[20] Rozzi SL, Lephart SM, Sterner R, Kuligowski L, Balance training for persons with functionally unstable ankles. J Orthop Sports Phys Ther, 29(8), 1999, 478-486. 